\title{
NOTIZEN
}

\section{A New Continuous-Wave CO Chemical Laser from the Oxidation of Acetylene}

\section{F.G. SADIE*, P.A. BÜGeR and O.G. MALAN}

National Physical Research Laboratory, C.S.I.R., Pretoria, South Africa

(Z. Naturforsch. 28 a, 309-310 [1973]; received 14 December 1972)

Continuous-wave stimulated emission resulting from the oxidation of acetylene has been observed. Thirteen vibrational transitions of the first overtone band of $\mathrm{CO}$ have been resolved. The mechanism for laser action is proposed.

Continuous-wave (cw) laser action in both the fundamental ${ }^{1}$ and overtone bands ${ }^{2}$ of $\mathrm{CO}$, resulting from the oxidation of carbon disulphide has been reported. Pulsed stimulated emissions in the fundamental band of $\mathrm{CO}$ from the oxidation of $\mathrm{C}_{3} \mathrm{O}_{2}$ have also been observed $^{3}$. We now wish to report on a new $\mathrm{cw} \mathrm{CO}$ chemical laser in the overtone band from the oxidation of acetylene.

An internal mirror systems was employed. The resonator cavity was one meter in length and the mirrors, each with a $3 \mathrm{~m}$ radius of curvature were gold plated. The downstream mirror had a $3 \mathrm{~mm}$ coupling hole with $\mathrm{a} \mathrm{CaF}_{2}$ window.

Atomic oxygen was produced either by means of a transformer discharge or a microwave discharge.

Under conditions of low partial pressures of acetylene $(\approx 0.05$ Torr $)$ and of oxygen ( 1.0 Torr $)$ with helium as a buffer gas at a partial pressure of 4.5 Torr, $\mathrm{cw}$ stimulated emission was observed in the first overtone band $(2.3-2.8 \mu \mathrm{m})$ of $\mathrm{CO}$ using an uncooled $\mathrm{PbS}$ detector coupled to a synchronous amplifier.

The overtone output was analysed spectroscopically with a $\mathrm{lm}$ Czerny-Turner monochromator. Lasing overtone transitions from $v=14-12$ down to $v=2-0$ were resolved.

Figure 1 is a comparison of the overtone spectrum obtained from the $\mathrm{C}_{2} \mathrm{H}_{2}-\mathrm{O}_{2}$ system with that obtained from the $\mathrm{CS}_{2}-\mathrm{O}_{2}$ system ${ }^{4}$. There is a marked shift in the intensity distribution and it appears that in the oxidation of acetylene, $\mathrm{CO}$ vibrational levels up to $v=14$ are populated as compared to $v=16$ in the $\mathrm{CS}_{2}$ oxidation. The spectrum is similar to that observed from the chemiluminescence of the acetylene oxidation 5 .

Mechanistic and kinetics studies of the oxidation have been reported 6 and it appears that the major elementary reactions responsible for the production of vibrationally excited $\mathrm{CO}$ are:

$\mathrm{O}+\mathrm{C}_{2} \mathrm{H}_{2} \rightarrow \mathrm{CH}_{2}+\mathrm{CO}+50.5 \mathrm{kcal} \mathrm{mole}^{-1}$,

$\mathrm{O}+\mathrm{CH}_{2} \rightarrow \mathrm{CO}+2 \mathrm{H}+75 \mathrm{kcal} \mathrm{mole}-1$.

* On leave from the University of the Western Cape, Private Bag, Bellville, South Africa.
The elementary reaction (1) is rate determining. It has a rate constant of about $1.5 \times 10^{-13} \mathrm{cc}^{\text {molecule }}{ }^{-1} \mathrm{sec}^{-1}$ independent of pressure in the range 0.9 Torr to 9 Torr. Its activation energy is $<1 \mathrm{kcal} \mathrm{mole}^{-1}$. The subsequent reaction which yields stable products is much faster than the initial reaction. The heats of reaction

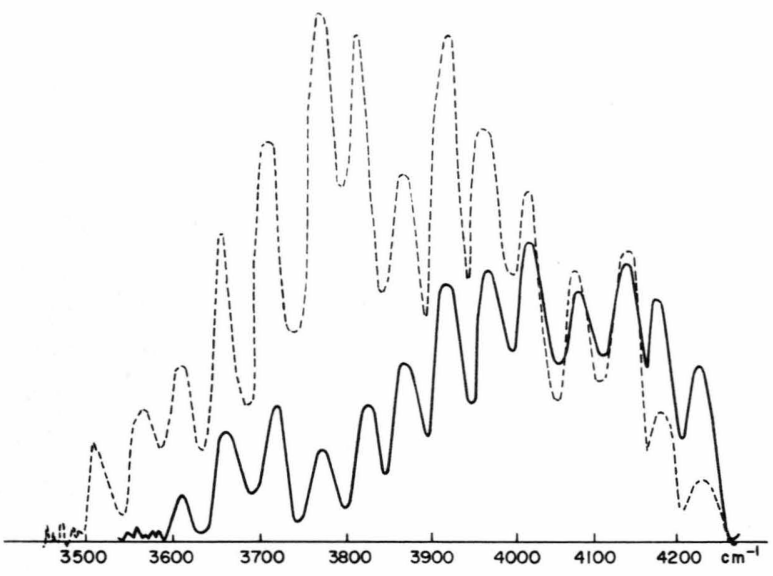

Fig. 1. Comparison of $\mathrm{CO}$ overtone spectra obtained from two distinct systems.

Spectrum obtained from the system $\mathrm{O}_{2}-\mathrm{C}_{2} \mathrm{H}_{2}$;

- - - - Spectrum obtained from the system $\mathrm{O}_{2}-\mathrm{CS}_{2}$.

were calculated from tabulated values of the thermodynamic properties of the participating species?

The heat of reaction (2) is sufficient to populate vibrational levels of $\mathrm{CO}$ up to and including $v=14$, provided all of the heat is converted to $\mathrm{CO}$ vibrational energy.

The exothermal energy release of the elementary reactions given above is of the same order of magnitude as in the case of the oxidation of $\mathrm{CS}_{2}$. The observed overtone spectrum, however, shows a very definite shift in the intensity distribution and the individual lines also have much lower intensities than in the case of the $\mathrm{CS}_{2}-\mathrm{O}_{2}$ laser (Figure 1). This could possibly be ascribed to the following:

(a) The heats of reaction are distributed over many more reaction products and are converted to vibrations and translations of these, thus lowering the energy available for the excitation of $\mathrm{CO}$.

(b) Vibrational deactivation of excited $\mathrm{CO}$ through collisions with other and a larger number of reaction products and intermediates.

Laser action was also observed to be more sensitive to changes in the total pressure than in the case of the 
$\mathrm{CS}_{2}-\mathrm{O}_{2}$ laser. Provisional experiments seem to indicate that the maximum total pressure at which gain still exceeds collisional deactivation is much lower than with the $\mathrm{CS}_{2}-\mathrm{O}_{2}$ laser.

\section{References}

1 C. J. Wittig, J. C. Hassler, and P. D. Coleman, J. Chem. Phys. 55, 5523 (1971).

2 F.G. Sadie, P.A. Büger and O.G. Malan, J. Appl. Phys. 43, 2906 (1972).
3 M.C. Lin and S.H. Bauer, Chem. Phys. Lett. 7, 223 (1970), J. Chem. Phys. 54, 5423 (1971).

4 F.G. Sadie, P.A. Büger, and O.G. Malan, J. Appl. Phys. 43, 5141 (1972).

5 D. M. Creek, C.M. Melliar-Smith, and N. Jonathan, J. Chem. Soc. (A) 1970, 646.

6 C.A. Arrington, W. Brennen, G.P. Glass, J.V. Michael, and H. Niki, J. Chem. Phys. 43, 525 (1965). J.M. Brown and B.A. Thrush, Trans. Faraday Soc. 63, 630 (1967)

7 U.S. Dept. of Commerce: National Bureau of Standards Selected Values of Chemical Thermodynamic Properties (1968). 